\section{Gigantism and Acromegaly Due to Xq26 Microduplications and GPR101 Mutation}

\author{
G. Trivellin, A.F. Daly, F.R. Faucz, B. Yuan, L. Rostomyan, D.O. Larco, \\ M.H. Schernthaner-Reiter, E. Szarek, L.F. Leal, J.-H. Caberg, E. Castermans, \\ C. Villa, A. Dimopoulos, P. Chittiboina, P. Xekouki, N. Shah, D. Metzger, \\ P.A. Lysy, E. Ferrante, N. Strebkova, N. Mazerkina, M.C. Zatelli, M. Lodish, \\ A. Horvath, R. Bertollo de Alexandre, A.D. Manning, I. Levy, M.F. Keil, \\ M. de la Luz Sierra, L. Palmeira, W. Coppieters, M. Georges, L.A. Naves, \\ M. Jamar, V. Bours, T.J. Wu, C.S. Choong, J. Bertherat, P. Chanson, P. Kamenický, \\ W.E. Farrell, A. Barlier, M. Quezado, I. Bjelobaba, S.S. Stojilkovic, J. Wess, \\ S. Costanzi, P. Liu, J.R. Lupski, A. Beckers, and C.A. Stratakis
}

A BSTRACT
Increased secretion of growth hormone leads to gigantism in children and acromegaly in adults; the genetic causes of gigantism and acromegaly are poorly understood.

\section{METHODS}

We performed clinical and genetic studies of samples obtained from 43 patients with gigantism and then sequenced an implicated gene in samples from 248 patients with acromegaly.

\section{RESULTS}

We observed microduplication on chromosome Xq26.3 in samples from 13 patients with gigantism; of these samples, 4 were obtained from members of two unrelated kindreds, and 9 were from patients with sporadic cases. All the patients had disease onset during early childhood. Of the patients with gigantism who did not carry an Xq26.3 microduplication, none presented before the age of 5 years. Genomic characterization of the Xq26.3 region suggests that the microduplications are generated during chromosome replication and that they contain four protein-coding genes. Only one of these genes, GPR101, which encodes a G-protein-coupled receptor, was overexpressed in patients' pituitary lesions. We identified a recurrent GPR101 mutation (p.E308D) in 11 of 248 patients with acromegaly, with the mutation found mostly in tumors. When the mutation was transfected into rat GH3 cells, it led to increased release of growth hormone and proliferation of growth hormone-producing cells.

\section{CONCLUSIONS}

We describe a pediatric disorder (which we have termed X-linked acrogigantism [X-LAG]) that is caused by an Xq26.3 genomic duplication and is characterized by early-onset gigantism resulting from an excess of growth hormone. Duplication of GPR101 probably causes X-LAG. We also found a recurrent mutation in GPR101 in some adults with acromegaly. (Funded by the Eunice Kennedy Shriver National Institute of Child Health and Human Development and others.)
The authors' full names, academic degrees, and affiliations are listed in the Appendix. Address reprint requests to Dr. Stratakis at 10 Center Dr., Bldg. 10, National Institutes of Health, Clinical Research Center, Rm. 1-3330, MSC1103, Bethesda, MD 208921862, or at stratakc@mail.nih.gov; or to Dr. Beckers at the Department of Endocrinology, Centre Hospitalier Universitaire de Liège (B35), Domaine Universitaire du Sart-Tilman, 4000 Liege, Belgium, or at albert.beckers@chu.ulg.ac.be.

Drs. Trivellin and Daly, and Drs. Beckers and Stratakis, contributed equally to this article.

This article was published on December 3 , 2014, at NEJM.org.

DOI: 10.1056/NEJMoal408028

Copyright (c) 2014 Massachusetts Medical Society. 
OMATIC GROWTH IS ORCHESTRATED BY A complex hormonal crosstalk involving the hypothalamus, pituitary, and peripheral tissues. ${ }^{1}$ Genetic disorders that affect this network can lead to increased secretion of growth hormone, which results in acromegaly. If the excess in growth hormone occurs before epiphyseal fusion, the result can be gigantism. Nonsyndromic gigantism is most frequently caused by pituitary adenomas occurring as familial isolated pituitary adenomas or sporadically, usually as a result of mutations in the gene encoding aryl hydrocarbon receptor-interacting protein (AIP). ${ }^{2-4}$ Other monogenic diseases can cause gigantism, but most of these conditions develop in adulthood in association with other tumors. ${ }^{5}$ In young children, somatic overgrowth that is due to an excess of growth hormone is rare, and the cause is unknown. Other syndromic genetic overgrowth conditions in children, such as the Sotos syndrome and the Simpson-Golabi-Behmel syndrome, are not associated with pituitary abnormalities. ${ }^{6,7}$

We report a striking phenotype of gigantism that has an onset in early childhood and that is caused by an excess of growth hormone. The disorder is associated with heritable microduplications on chromosome Xq26.3. There are four genes in the duplicated stretch of DNA; one of these, GPR101, encodes an orphan G-proteincoupled receptor and is probably the gene that drives the phenotype in young children and the growth of sporadic growth hormone-producing adenomas in some patients with acromegaly.

\section{METHODS}

\section{PATIENTS}

We analyzed samples obtained from 43 patients with gigantism who had hypersecretion of growth hormone, evidence of an anterior pituitary lesion on magnetic resonance imaging, a height on country-specific growth charts of either more than the 97th percentile or more than 2 SD above the mean height for age, and negative test results for mutations or deletions in genes associated with pituitary adenomas (Table 1). Details with respect to one family with this syndrome $^{8,9}$ and two patients with sporadic disease $^{10,11}$ have been described previously.

\section{GENETIC ANALYSES}

We sequenced the four genes in the duplicated region on chromosome Xq26.3 in 259 germline and tumor DNA samples that were obtained from 248 patients with sporadic acromegaly (Table S1 in the Supplementary Appendix, available with the full text of this article at NEJM.org). We sequenced GPR101 and performed array comparative genomic hybridization $(\mathrm{aCGH})$ on germline DNA in samples obtained from 13 families with familial isolated pituitary adenomas without AIP mutations. We used quantitative reverse-transcriptase-polymerase-chain-reaction (qRT-PCR) assays to measure the expression levels of duplicated genes in both leukocytes and pituitary tumors. We performed comparative protein-structure modeling on GPR101 using Modeller software, version 9.13.12 We determined the level of growth hormone and cyclic AMP (cAMP) and the rate of cellular proliferation after transient overexpression of each of the four implicated genes in $\mathrm{GH} 3$ cells obtained from rat pituitary tumors.

\section{STUDY OVERSIGHT}

The institutional review board at each of the participating institutions approved our studies. We studied the anonymized samples from international acromegaly cohorts with approval from the National Institutes of Health Intramural Office for Human Research Protections. Written informed consent was obtained from all adult patients and parents or guardians of children with early-onset gigantism.

\section{RESULTS}

\section{CLINICAL PRESENTATION}

The clinical and biochemical characteristics of the 43 patients who had nonsyndromic gigantism without abnormalities in genes associated with pituitary tumors are presented in Table 1. Genetic analyses delineated two phenotypes: an early-childhood form of gigantism with a typical onset in late infancy (Fig. 1) and a second form with a typical onset in adolescence.

\section{IDENTIFICATION OF Xq26.3 MICRODUPLICATION}

We detected microduplications on chromosome Xq26.3 in samples obtained from patients with the early-childhood form of gigantism (Fig. 2, and Fig. S1, S2, and S3 in the Supplementary Appendix). Nine of the 13 patients with an Xq26.3 microduplication and the 1 probable carrier (an affected mother with gigantism) were female and were of normal size at birth. All the patients grew rapidly during infancy, attaining a median 


\begin{tabular}{|c|c|c|c|}
\hline Characteristic & $\begin{array}{l}\text { Xq26.3 Microduplication } \\
(\mathrm{N}=14)\end{array}$ & $\begin{array}{l}\text { No Xq26.3 Microduplication } \\
(\mathrm{N}=29)\end{array}$ & $\begin{array}{c}P \\
\text { Value }\end{array}$ \\
\hline Female sex - no. (\%) & $10(71)$ & $7(24)$ & 0.007 \\
\hline Median age at onset of rapid growth (range) - yr & $1.0(0.5$ to 2.0$)$ & $16.0(5.0$ to 18.0$)$ & $<0.001$ \\
\hline Median age at diagnosis (range) $-\mathrm{yr}$ & 3 (1 to 22$)$ & $21(5$ to 34$)$ & $<0.001$ \\
\hline Median height at diagnosis (range) $-\mathrm{cm}$ & 116 (99 to 175$)$ & 187 (171 to 209$)$ & $<0.001$ \\
\hline $\begin{array}{l}\text { Median standard-deviation score for height at } \\
\text { diagnosis (range) }\end{array}$ & $+3.8(+1.9$ to +7.1$)$ & $+3.3(+2.1$ to +5.8$)$ & 0.45 \\
\hline $\begin{array}{l}\text { Elevated levels of growth hormone and insulin-like } \\
\text { growth factor } 1 \text { at diagnosis - no. (\%) }\end{array}$ & $14(100)$ & $29(100)$ & 1.00 \\
\hline $\begin{array}{l}\text { No suppression of growth hormone during oral } \\
\text { glucose-tolerance test - no. (\%) }\end{array}$ & $14(100)$ & $29(100)$ & 1.00 \\
\hline $\begin{array}{c}\text { Median factor increase in insulin-like growth factor } 1 \\
\text { at diagnosis (range) - multiple of ULN }\end{array}$ & $4.4(2.4$ to 5.2$)$ & 2.1 (1.4 to 5.3$)$ & 0.005 \\
\hline Elevated prolactin level at diagnosis - no. (\%) & $13(93)$ & $6(21)$ & $<0.001$ \\
\hline Median maximum tumor diameter (range) $-\mathrm{cm}$ & 16 (10 to 39$)$ & 20 (9 to 41$)$ & 0.16 \\
\hline \multicolumn{4}{|l|}{ Adenoma or hyperplasia — no. $(\%) \dagger$} \\
\hline Both adenoma and hyperplasia & $2(14)$ & 0 & \\
\hline Adenoma only & $10(71)$ & $29(100)$ & - \\
\hline Hyperplasia only & $1(7)$ & 0 & \\
\hline \multicolumn{4}{|l|}{ Type of syndrome — no. (\%) } \\
\hline Sporadic & $9(64)$ & $29(100)$ & - \\
\hline Familial & $5(36) ‡$ & 0 & \\
\hline Siblings with normal growth — no./total no. (\%) & $9 / 11(82)$ & $29 / 29(100)$ & - \\
\hline
\end{tabular}

* ULN denotes upper limit of the normal range.

$\dagger$ The presence of hyperplasia or adenoma could not be determined in one patient who did not undergo surgery.

In one patient with the familial syndrome, pituitary gigantism was diagnosed in the mother and son at the same visit,

when the son was 8 years of age and the mother was 22 years of age. The mother had had tall stature and acromegalic features since childhood for which she had not been referred for medical attention. The clinical data for the mother, for whom DNA was not available, are included.

height score of $+3.8 \mathrm{SD}$ at diagnosis (median age, 36 months). At the time of diagnosis, they showed marked overall somatic growth, with elevated weight and an enlarged head circumference (median, $51.2 \mathrm{~cm}$ ). The onset of accelerated growth and the onset of accelerated weight gain usually coincided but were not always synchronous (Fig. 1, and Fig. S4 in the Supplementary Appendix). As compared with patients who did not have an Xq26.3 microduplication, those with the microduplication had an earlier median age at the onset of abnormal growth (12 months vs. 16 years), an increased acceleration in height, and elevated levels of insulin-like growth factor 1 and prolactin (Table 1). We did not observe precocious puberty in the microduplication carriers. Levels of peripheral growth hormone-releasing hormone did not suggest ectopic secretion of this hormone, and nuclear imaging scans were negative for other tumors.

Of the 13 patients who underwent surgery, 10 had pituitary macroadenomas alone (median maximum diameter, $16 \mathrm{~mm}$ ), and 3 patients had pituitary hyperplasia, with or without an identified adenoma (Fig. 3H). In all the patients, hormonal control was not achieved with medical therapy alone. Such control required either radical or repeated neurosurgery alone (in 4 patients) or in combination with the administration of the growth hormone receptor antagonist pegvisomant (in 3 patients) or radiotherapy (in 2 patients). Seven patients had permanent hypopituitarism at the time of this study.

The common duplicated genomic segment was approximately $500 \mathrm{~kb}$ in length, from position $135,627,637$ to $136,118,269$ (GRCh37/hg19) 


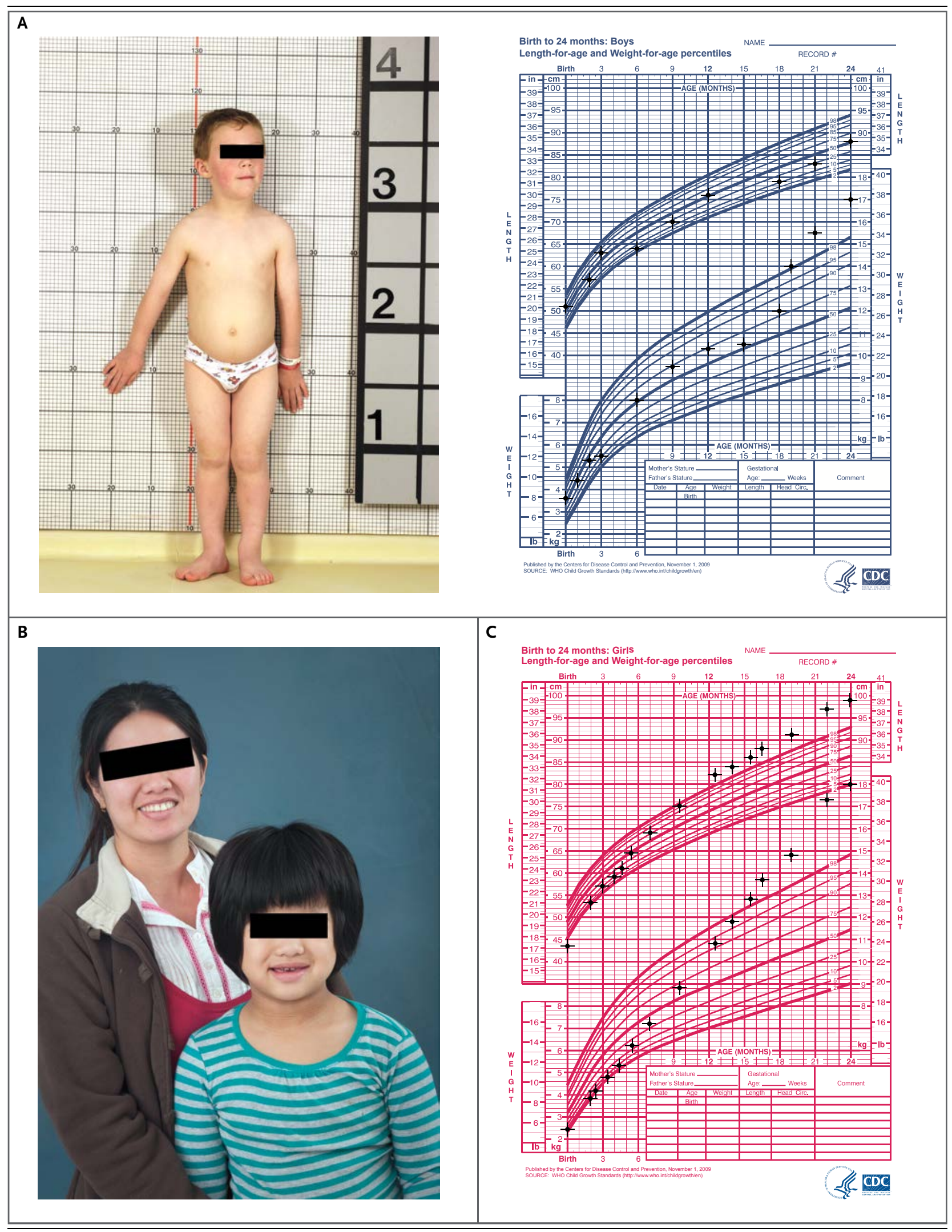


Figure 1 (facing page). Familial and Sporadic Cases of Gigantism and Male and Female Growth Patterns Due to the Xq26.3 Microduplications.

Panel A shows Patient F1C, who has familial gigantism, at the age of 3 years. His growth chart up to 24 months of age shows the rapid acceleration in weight, although the acceleration in height did not begin until after his second birthday (Fig. S4 in the Supplementary Appendix). Panel B shows an unaffected mother and her daughter (Patient S6), who has sporadic gigantism and whose height was $120 \mathrm{~cm}$ at the age of 3 years. A growth chart for Patient S4 (Panel C), another girl with sporadic gigantism, illustrates the typical early increase in height and weight seen in patients with Xq26.3 microduplications, starting at the age of 6 months in this child.

(Fig. 2). One patient had a complex genomic rearrangement, with two duplicated segments that were separated by a short region of normal genomic sequence. No other patterns of duplication or deletion or homozygosity were shared among the affected patients. One family with familial isolated pituitary adenomas included an affected mother and two affected sons (who have been described previously ${ }^{8}$ ) with the same Xq26.3 microduplication; the unaffected father did not have the duplication. In another family with this condition, the mother had childhoodonset gigantism and a histologically confirmed pituitary macroadenoma but had died of complications of hypopituitarism. She had two children: the son carried the Xq26.3 microduplication and had childhood-onset gigantism (Patient F2A), and the healthy daughter did not have the duplication. The most parsimonious explanation is that the son inherited the X-linked disease from his carrier mother. Hence, Xq26.3 microduplications can be considered to be a new pathogenic explanation in certain kindreds with familial isolated pituitary adenomas that have acrogigantism without AIP mutations.

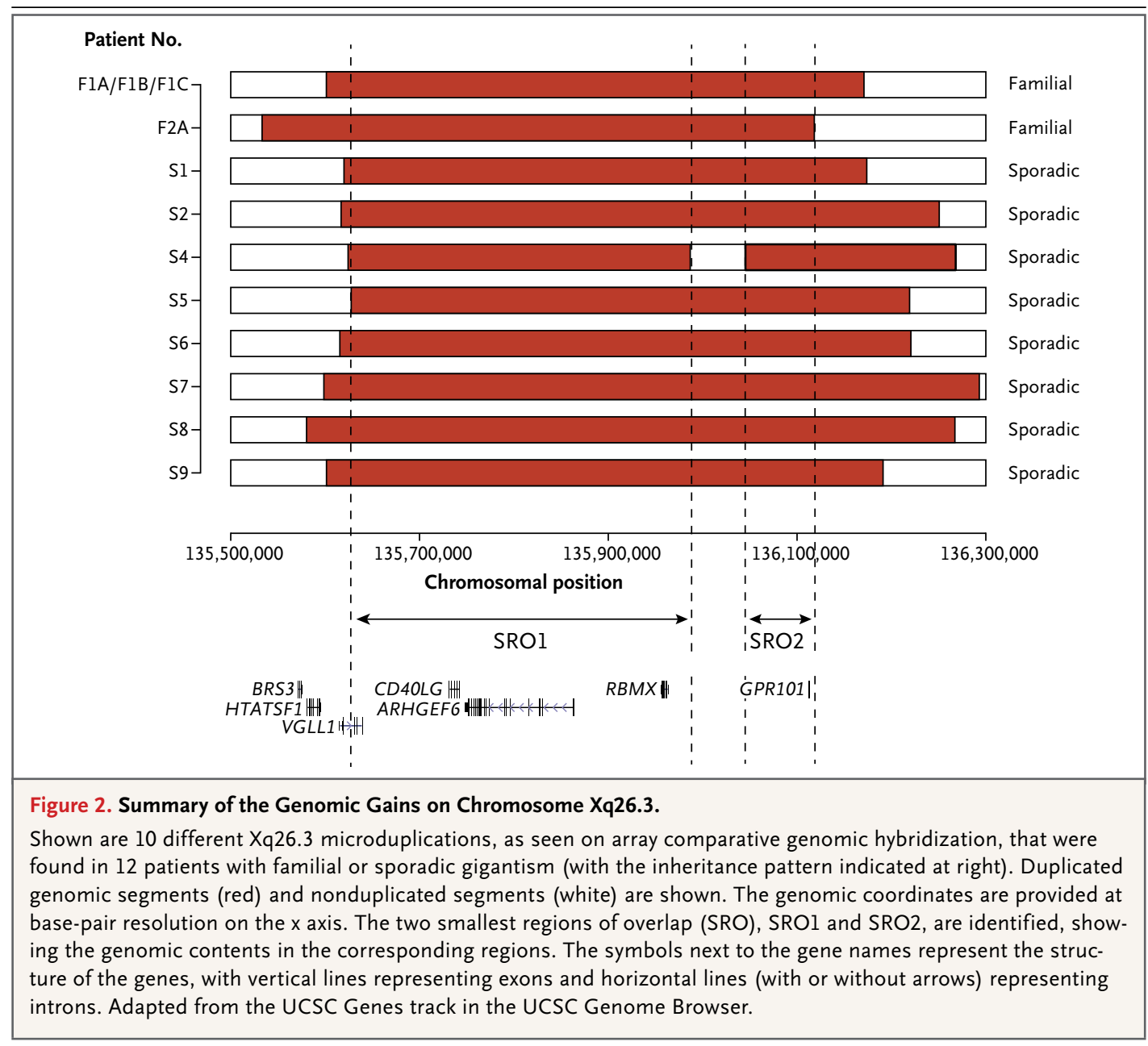




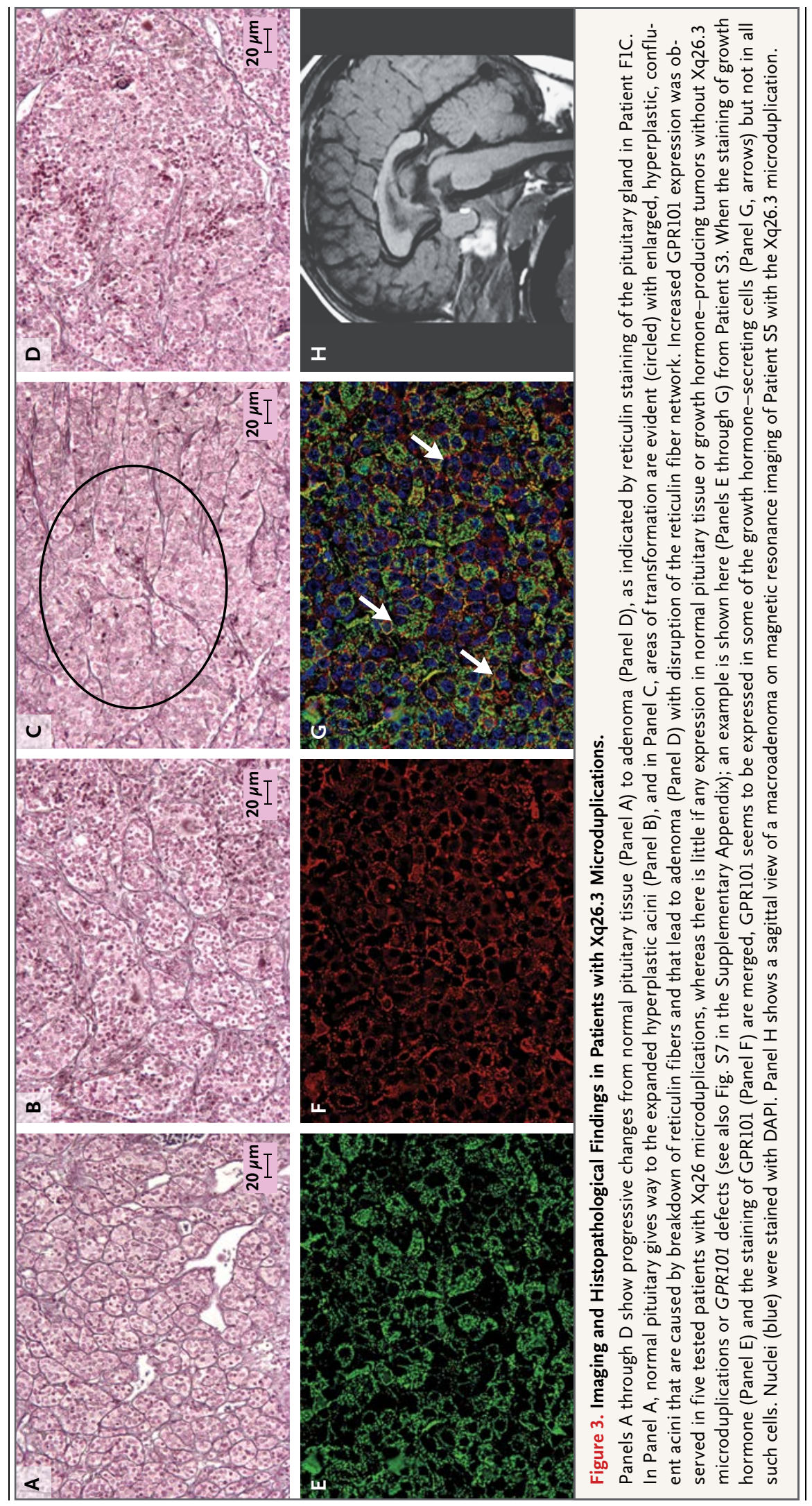




\section{FURTHER CHARACTERIZATION OF Xq26.3} MICRODUPLICATION

Using high-definition analysis of the critical duplicated region, we analyzed 10 distinct genomic duplications in 12 patients, including 4 patients with the familial form of the disease and 8 patients with the sporadic form (Fig. S1 and S3 in the Supplementary Appendix). On genomewide aCGH, these mutations appeared to be simple duplications. However, using high-resolution aCGH, long-range PCR, and Sanger sequencing of the breakpoints, we found various underlying genomic complexities (Fig. S3 in the Supplementary Appendix).

All sporadic Xq26.3 duplications were nonrecurrent; the boundaries of the duplicated segment were unique to each patient. On both aCGH and breakpoint PCR assays, samples obtained from unaffected parents and siblings of patients with sporadic disease showed negative results, documenting the microduplication as a new mutation (Fig. S3A and S5A in the Supplementary Appendix). The same duplication was transmitted from an affected mother (Patient F1A) to her affected offspring, Patients F1B and F1C (Fig. 2, and Fig. S3 and S5B in the Supplementary Appendix).

The duplicated genomic regions that were shared by all affected persons consisted of the two smallest regions of overlap (SRO), which were designated as SRO1 and SRO2 (Fig. 2). SRO1 (chromosomal position, 135,627,637 to 135,986,830; hg19) encompassed three genes in the Online Mendelian Inheritance in Man (OMIM) database: CD40LG (OMIM number, 300386), ARHGEF6 (OMIM number, 300267), and RBMX (OMIM number, 300199), whereas SRO2 (chromosomal position, 136,045,310 to $136,118,269$; hg19) included GPR101 (OMIM number, 300393) (Fig. 2).

\section{INVESTIGATION OF CANDIDATE GENES}

Sequencing of each of the four genes in the 43 patients with gigantism did not reveal any singlenucleotide variants of likely pathogenicity. A quantitative RT-PCR assay of pituitary tumor RNA from 2 patients with Xq26.3 microduplications suggested that CD4OLG was not expressed in the pituitary tumors. Neither ARHGEF6 nor RBMX showed up-regulated expression in the pituitary tumors of 2 patients with the duplication (Fig. 4). In contrast, the expression of GPR101 in the pituitaries of the children carrying an Xq26.3 duplication was increased by a factor as high as 1000 , as compared with unaffected pituitary tissue and pituitary tumors from persons who tested negative for microduplications (Fig. 4A). This result was confirmed at the protein level by increased immunostaining for GPR101 in pituitary tumors from patients with Xq26.3 duplications (Fig. 3G, and Fig. S7 in the Supplementary Appendix). Experimental overexpression of ARHGEF6, RBMX, and GPR101 alone in the rat GH3 cell line did not significantly increase either cell proliferation or the secretion of growth hormone (Fig. 4D and 4E, and Fig. S8 in the Supplementary Appendix). Nonmutated GPR101 in combination with ARHGEF6, RBMX, or both modestly increased cell proliferation but not the secretion of growth hormone (Fig. S8 in the Supplementary Appendix).

The X-chromosome-inactivation pattern was random in the female patients with sporadic disease and skewed in Patient F1A, who had familial disease; $\mathrm{CpG}$ islands were identified in silico only in RBMX and GPR101 (Fig. S9 and S10 in the Supplementary Appendix).

\section{IDENTIFICATION OF P.E308D MUTATION IN GPRIO1}

In a series of 248 patients with sporadic acromegaly, none carried a microduplication at Xq26.3. However, 11 patients had a c.924G $\rightarrow$ C substitution (p.E308D) in GPR101, which was not found in 7600 control samples obtained from public databases (Tables S1 and S2 in the Supplementary Appendix). Of the 11 mutation carriers, 3 appeared to carry a constitutive mutation, which was detected in DNA from peripheralblood mononuclear cells (PBMCs). We detected the mutation in the tumor DNA in the remaining 8 patients (Fig. 5A). In one patient, we determined that the mutation was a de novo somatic mutation - that is, the GPR101 mutation occurred only in the tumor DNA sequence and not in the PBMC sequence (Fig. 5B). None of the 13 families with familial isolated pituitary adenomas carried the p.E308D mutation in GPR101.

GPR101 encodes an orphan G-protein-coupled receptor that is highly expressed in rodent hypothalamus (Fig. S11 and S12 in the Supplementary Appendix) and is predicted to couple to the stimulatory $G$ protein $\left(G_{s}\right)$, a potent activator of adenylyl cyclase. ${ }^{13,14} \mathrm{~A}$ model of human GPR101 in complex with a $\mathrm{G}_{\mathrm{s}}$ heterotrimer shows the physical relationship between the p.E308D amino acid change and the activating p.A397K change, a mutation that has been described previously. ${ }^{15}$ The two amino acids, which are predicted to be 


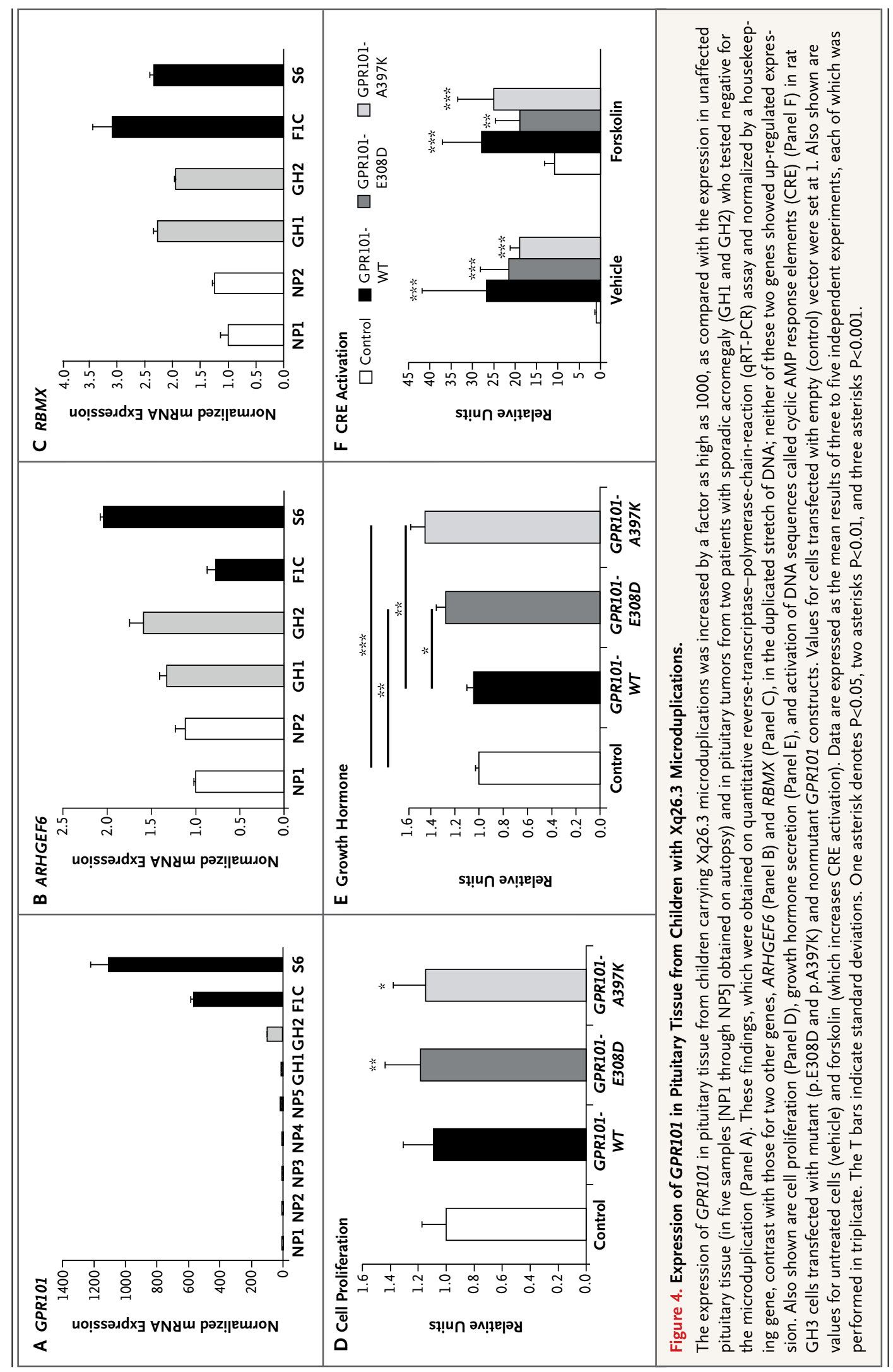




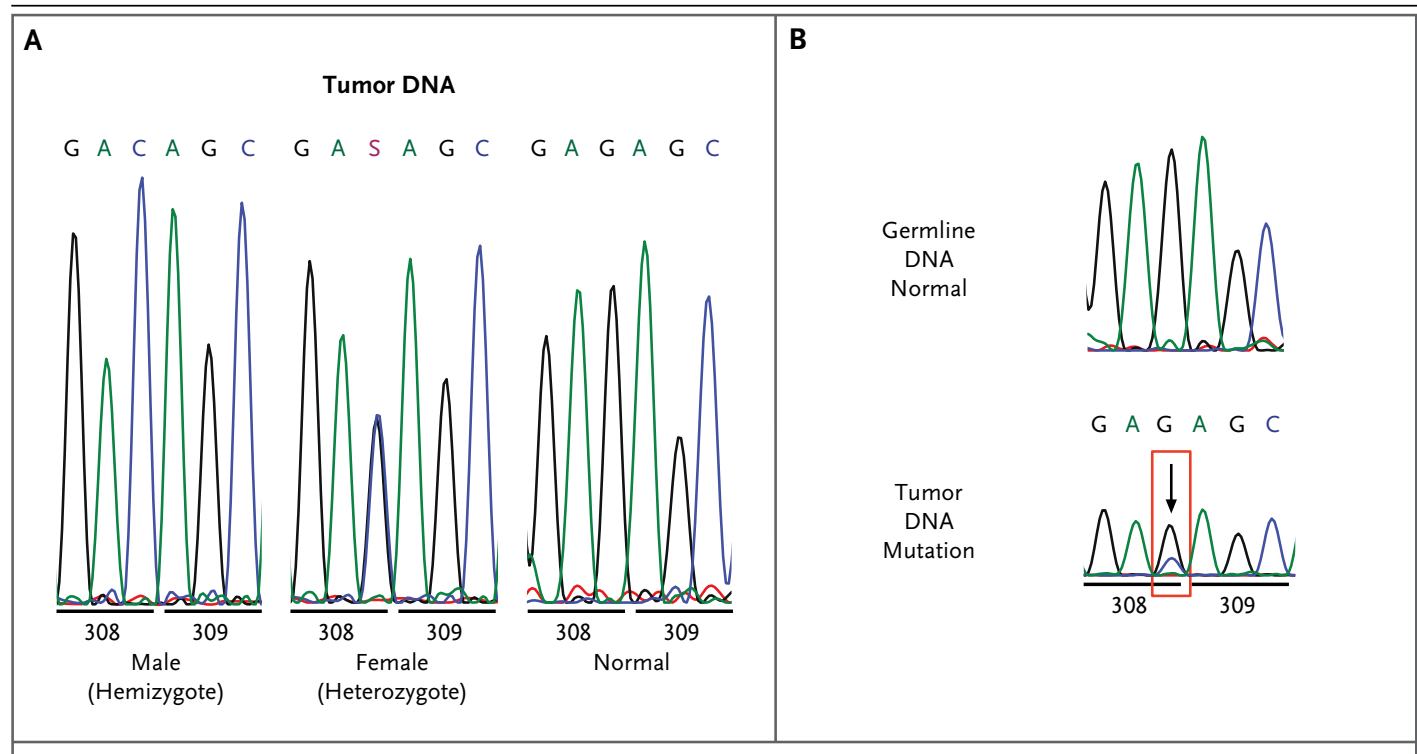

C

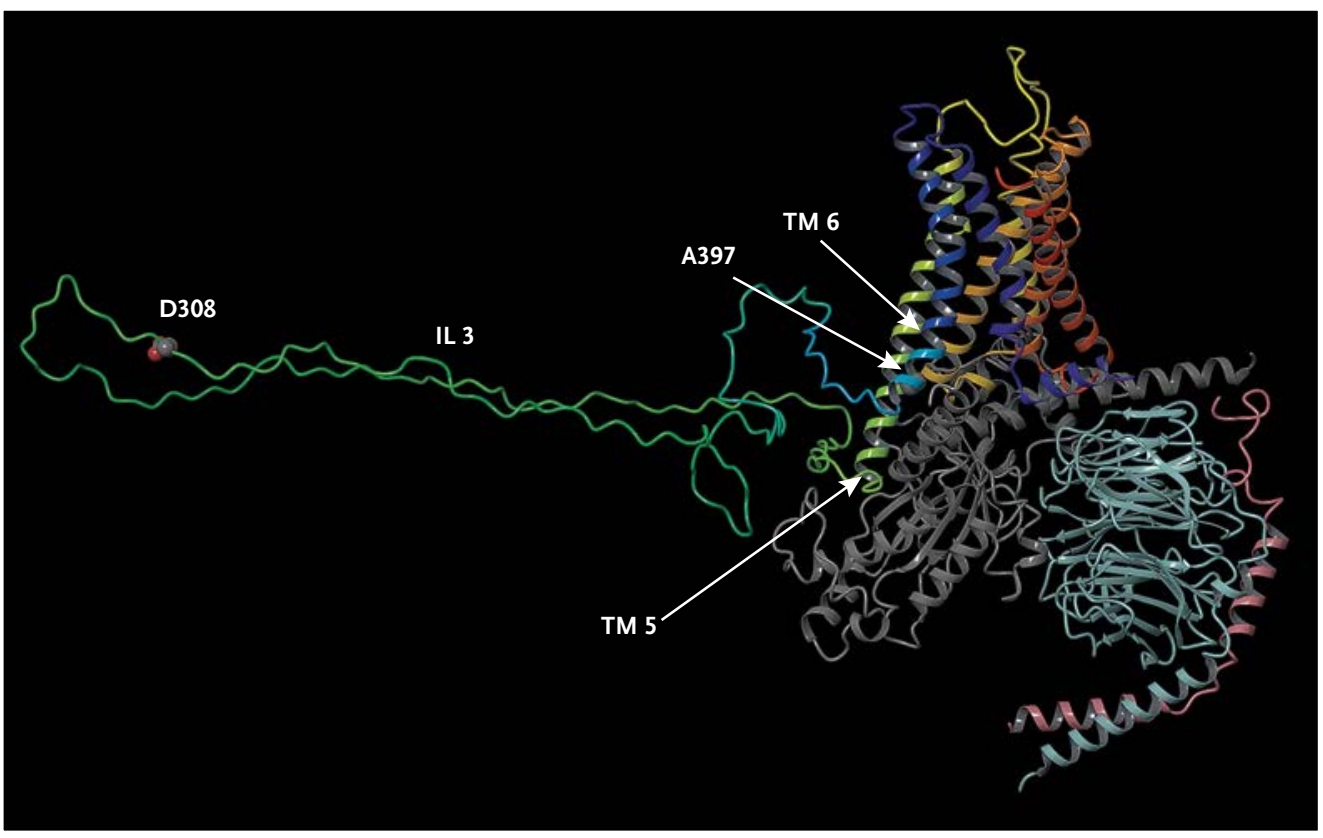

Figure 5. Effect of the p.E308D Mutation in GPR101 in 11 Patients with Sporadic Acromegaly.

Panel A shows the sequence for GPR101 in growth hormone-producing pituitary tumors obtained from patients with sporadic acromegaly, as compared with normal tissue. Panel B shows results for a patient with a somatic mutation, which was determined by the presence of the mutation in the GPR101 sequence of DNA in the tumor sample but not in the sequence in peripheral-blood mononuclear cells. None of the 13 families with familial isolated pituitary adenomas carried the p.E308D mutation in GPR101. Panel C shows a structural model of GPR101 bearing the p.E308D mutation. Residue A397 is located at the cytosolic end of transmembrane (TM) 6 of GPR101. The mutated D308 residue and the nonmutated A397 residue are shown in space-filling representation and colored according to elements, with carbon atoms in gray, oxygen atoms in red, and nitrogen atoms in blue. The backbone of the receptor and the $G$ protein heterotrimer is schematically represented as a ribbon, with the receptor shown with a spectrum of colors that ranges from red at the $\mathrm{N}$-terminal to purple at the $\mathrm{C}$-terminal; the $\alpha, \beta$, and $\gamma$ subunits of the $\mathrm{G}$ protein are in gray, blue, and pink, respectively. The cytosolic ends of TM 5 and TM 6 and intracellular loop (IL) 3, which connects them, are indicated by labels. The blue arrows show directions of the $\beta$-sheet domains of the $\beta$ subunit of the $\mathrm{G}$ protein. 
affected by the mutations, are on the cytosolic side of the receptor (Fig. 5C). The E308 residue is located in the long intracellular loop 3, which connects transmembrane domains 5 and 6 .

Overexpression of the p.E308D and p.A397K mutants, but not of nonmutant GPR101, significantly increased cell proliferation and secretion of growth hormone in rat GH3 cells (Fig. 4D and $4 \mathrm{E})$. As in the construct containing the nonmutant receptor, the two mutant constructs resulted in increased cAMP signaling in GH3 cells in an in vitro reporter assay, both at baseline and in the presence of $10 \mu \mathrm{M}$ forskolin, a direct stimulator of adenylyl cyclase (Fig. 4F).

\section{DISCUSSION}

Several lines of evidence support the identification of a new pituitary gigantism syndrome in young children carrying microduplications on chromosome Xq26.3, a disorder that is probably caused by GPR101 overexpression. We propose that this syndrome be called X-linked acrogigantism (X-LAG). First, we did not find disruption of Xq26.3 in patients with later-onset gigantism (Table 1). Second, the finding that patients with other conditions had different duplications within the same region narrowed our focus to the smallest region of overlap. A duplication encompassing CD4OLG and ARHGEF6 but not RBMX and GPR101 occurred in a family with low birth weight, intellectual disability, and craniofacial abnormalities, ${ }^{16}$ which suggests that duplications with the exclusion of RBMX and GPR101 do not lead to gigantism. Third, short stature has been reported in several patients with deletions in this region, which suggests that the absence of these genes may lead to the opposite phenotype (Table S4 in the Supplementary Appendix). ${ }^{16-18}$ Other investigators have described at least 15 additional patients with the same phenotype of early-onset growth who may be good candidates for a diagnosis of X-LAG (Table S3 in the Supplementary Appendix).

The breakpoint features of Xq26.3 duplications suggest that they were generated by means of a replication-based mechanism that underlies the genesis of other copy-number variants (CNVs) and the pathogenesis of other genomic disorders. ${ }^{19}$

The cytogenetic data narrowed the smallest region of overlap to a segment spanning CD40LG, ARHGEF6, RBMX, GPR101, one microRNA
(miR-934), and a small nucleolar RNA (SNORD61) of unknown function. We did not detect CD40LG expression in the pituitary tissues from our patients (Fig. 4). Messenger RNA for ARHGEF6 and $R B M X$ was expressed to a similar degree in affected and unaffected tissues from duplication carriers. Of all the genes and the noncoding RNAs in the duplicated segment, only GPR101 had markedly increased expression in the pituitary tumors from the duplication carriers (Fig. 4).

GPR101 is an orphan G-protein-coupled receptor that is strongly expressed in the hypothalamus in rodents (Fig. S11 and S12 in the Supplementary Appendix). ${ }^{13,14,20}$ It was recently shown that a fragment of the gonadotropin-releasing hormone could be a ligand for this receptor. ${ }^{21}$ The GPR101 protein may also play a role in hypothalamic control of energy homeostasis. ${ }^{22}$ The effect of a mutation (p.A397K) that is predicted to activate GPR101 when tested in vitro and in mice supports such a role. ${ }^{15}$ The pituitary-specific overexpression of GPR101 may be due to a gene-dose effect (as described in many genomic disorders ${ }^{23}$ ) or to an unknown promoter sequence created by the chromosomal rearrangement, although we did not identify any putative new promoter, or to perturbed chromatin regulation due to the genomic structural alteration from duplication CNVs. ${ }^{24,25}$ On the basis of our data from transfection experiments, we cannot rule out a modest contribution of RBMX and ARHGEF6 coexpression to cell proliferation. However, unlike GPR101, neither ARHGEF6 nor RBMX was overexpressed in the pituitary tumors from children with microduplications.

Our studies of sporadic acromegaly provide further support for a role of GPR101 in X-LAG. We found a recurrent GPR101 mutation, p.E308D, in $4.4 \%$ of DNA in tumor samples and in $1.9 \%$ of DNA in PBMC samples obtained from patients with isolated acromegaly. In at least one patient, the mutation was present only in the tumor DNA. We did not identify GPR101 mutations in families with familial isolated pituitary adenomas. A model of human GPR101 in complex with a $\mathrm{G}_{\mathrm{s}}$ heterotrimer showed that both the p.E308D mutation and the previously described p.A397K mutation ${ }^{15}$ are on the cytosolic side of the receptor that interacts with heterotrimeric $\mathrm{G}$ proteins. Residue E308 is located in a remarkably long intracellular loop, which connects two transmembrane domains. But in the absence of a model template for the GPR101 intracellular loop in which E308 resides, it is difficult to estimate the structural 
effect of the p.E308D substitution. However, transfection of a construct expressing GPR101 containing the p.E308D mutation increased proliferation and growth hormone secretion in a rat pituitary cell line. Moreover, we showed that GPR101 can strongly activate the cAMP pathway, for which the mitogenic effects in pituitary somatotropes are well established. ${ }^{26}$ These data further support a role for variant GPR101 in sporadic acromegaly.

The mechanism by which mutant GPR101 contributes to increased growth hormone secretion is unclear. Some of the patients with earlyonset gigantism whom we evaluated had normal or mildly elevated levels of circulating growth hormone-releasing hormone (but below the threshold required for ectopic tumoral secretion of this hormone), as was previously noted in Family F1. ${ }^{8}$ The tumor tissue showed strong expression of the growth hormone-releasing hormone receptor, in contrast to its expression of growth hormone-releasing hormone, which was low or absent (Fig. S15 in the Supplementary Appendix).

In conclusion, our results suggest that Xq26.3 microduplication is associated with a clinical syndrome of early-onset gigantism, which we have termed X-LAG. An increased dose of GPR101 on chromosome Xq26.3 probably causes the disease, and its activation by mutation occurs in patients with sporadic acromegaly. Xq26.3 microduplications may explain other historical cases of gigantism with features that closely resemble those of X-LAG. ${ }^{27,28}$ Our results offer an opportunity to study a new pathway involved in the central regulation of human growth.

Supported by a grant from the Intramural Research Program of the Eunice Kennedy Shriver National Institute of Child Health and Human Development (NICHD) (Z01-HD008920, to Dr. Stratakis), by a grant from the National Institute of Neurological Disorders and Stroke (NINDS) (RO1 NS058529), by a grant from the
National Human Genome Research Institute (U54HG006542, to Dr. Lupski), by a grant from Fonds d'Investissement de Recherche Scientifique of Centre Hospitalier Universitaire (CHU) de Liège (to Dr. Beckers), by an educational grant from Pfizer Belgium (to Dr. Beckers), and by the Jabbs Foundation (to Dr. Beckers). Computing resources used for the molecular-modeling component of this work were provided by the American University High Performance Computing System, which is funded in part by a grant from the National Science Foundation (BCS-1039497).

Disclosure forms provided by the authors are available with the full text of this article at NEJM.org.

We thank the patients and their families for their participation in this study; the nursing and other support staff at the NIH Clinical Research Center (CRC), in particular Dr. Edward Oldfield (now at the University of Virginia, Charlottesville) and Dr. Russell Lonser (now at Ohio State University, Columbus) who operated on most of the patients from the NIH who are described in this report; Dr. Phillip Gorden of the National Institute of Diabetes and Digestive and Kidney Diseases for providing a list of patients with acromegaly who have been seen at the NIH CRC during the past 30 years; Dr. Timothy Jones (Department of Pediatric Endocrinology, Princess Margaret Hospital for Children and School of Pediatrics and Child Health, University of Western Australia); Vincent Schram at the Microscopy and Imaging Core of the NICHD; Dr. Charalampos Lyssikatos and Dr. Monalisa Azevedo (Section on Endocrinology and Genetics, NICHD); Ms. Isabelle Besson and Dr. Michèle Bernier (Pathology and Cytology Department, Hôpital Foch, Suresnes, France); Drs. Antonella Forlino, Annalisa Vetro, and Orsetta Zuffardi (Department of Molecular Medicine, University of Pavia, Pavia, Italy); Dr. Anna Spada and Dr. Paolo Beck-Peccoz (Endocrinology and Diabetology Unit, Fondazione Istituto de Ricovero e Cura a Carattere Scientifico Ca' Granda Ospedale Maggiore Policlinico, Department of Clinical Sciences, University of Milan); Ms. Carine Mottard, Ms. Carine Deusings, Mr. Valery Leduc, and Ms. Nathalie Sacre (Department of Clinical Genetics, CHU de Liege, Liege, Belgium); Ms. Latifa Karim (GIGA-Genomics, Liège, Belgium); Dr. Silvia Paoletta (Laboratory of Bioorganic Chemistry, National Institute of Diabetes and Digestive and Kidney Diseases); Ms. Silke Williams (Laboratory of Pathology, National Cancer Institute); Dr. Jack A. Yanovski (Section on Growth and Obesity, NICHD); Dr. S.J. Levine (Cardiovascular and Pulmonary Branch, National Heart, Lung, and Blood Institute); Dr. Say Viengchareun (INSERM Unité 693 Le Kremlin-Bicêtre, France); Dr. Paul Hofman (Liggins Institute, University of Auckland, Auckland, New Zealand); Dr. Stephen Butler (Taranaki District Health Board, New Plymouth, New Zealand); Dr. Yvonne C. Anderson (Liggins Institute, University of Auckland, Auckland, New Zealand, and Taranaki Base Hospital, New Plymouth, New Zealand); Dr. Ian Holdaway (Auckland City Hospital and Greenlane Clinical Centre, Auckland, New Zealand); and Dr. Karen Carpenter (Department of Diagnostic Genomics, PathWest Laboratory Medicine Western Australia, Perth, Australia).

\section{APPENDIX}

The authors are as follows: Giampaolo Trivellin, Ph.D., Adrian F. Daly, M.B., B.Ch., Ph.D., Fabio R. Faucz, Ph.D., Bo Yuan, B.S., Liliya Rostomyan, M.D., Darwin O. Larco, Ph.D., Marie Helene Schernthaner-Reiter, M.D., Ph.D., Eva Szarek, Ph.D., Letícia F. Leal, Ph.D., Jean-Hubert Caberg, Ph.D., Emilie Castermans, Ph.D., Chiara Villa, M.D., Ph.D., Aggeliki Dimopoulos, M.D., Prashant Chittiboina, M.D., Paraskevi Xekouki, M.D., D.Sc., Nalini Shah, M.D., D.M., Daniel Metzger, M.D., Philippe A. Lysy, M.D., Ph.D., Emanuele Ferrante, M.D., Ph.D., Natalia Strebkova, M.D., Ph.D., Nadia Mazerkina, M.D., Ph.D., Maria Chiara Zatelli, M.D., Ph.D., Maya Lodish, M.D., Anelia Horvath, Ph.D., Rodrigo Bertollo de Alexandre, Ph.D., Allison D. Manning, M.Sc., Isaac Levy, M.D., Margaret F. Keil, Ph.D., P.N.P., Maria de la Luz Sierra, M.S., Leonor Palmeira, Ph.D., Wouter Coppieters, Ph.D., Michel Georges, M.D., Ph.D., Luciana A. Naves, M.D., Ph.D., Mauricette Jamar, M.D., Vincent Bours, M.D., Ph.D., T. John Wu, Ph.D., Catherine S. Choong, M.D., M.B., B.S., Jerome Bertherat, M.D., Ph.D., Philippe Chanson, M.D., Ph.D., Peter Kamenický, M.D., Ph.D., William E. Farrell, Ph.D., Anne Barlier, M.D., Ph.D., Martha Quezado, M.D., Ivana Bjelobaba, Ph.D., Stanko S. Stojilkovic, Ph.D., Jurgen Wess, Ph.D., Stefano Costanzi, Ph.D., Pengfei Liu, Ph.D., James R. Lupski, M.D., Ph.D., D.Sc., Albert Beckers, M.D., Ph.D., and Constantine A. Stratakis, M.D., D.Sc.

The author's affiliations are as follows: the Section on Endocrinology and Genetics, Program on Developmental Endocrinology and Genetics and Pediatric Endocrinology Interinstitute Training Program (G.T., F.R.F., M.H.S.-R., E.S., L.F.L., A.D., P.X., M.L., A.H., R.B.A., A.D.M., I.L., M.F.K., M.L.S., C.A.S.), and the Section on Cellular Signaling, Program in Developmental Neuroscience (I.B., S.S.S.), Eunice Kennedy Shriver National Institute of Child Health and Human Development, the Surgical Neurology Branch, National Institute of Neurological Disorders and Stroke (P. Chittiboina), Laboratory of Pathology, National Cancer Institute (M.Q.), and the 
Molecular Signaling Section, Laboratory of Bioorganic Chemistry, National Institute of Diabetes and Digestive and Kidney Diseases (J.W.) - all at the National Institutes of Health, and the Department of Obstetrics and Gynecology, Uniformed Services University of the Health Sciences (D.O.L., T.J.W.) - both in Bethesda, MD; the Departments of Endocrinology (A.F.D., L.R., C.V., A. Beckers) and Clinical Genetics (J.-H.C., E.C., M.J., V.B.), Centre Hospitalier Universitaire de Liège, University of Liège, Domaine Universitaire du Sart-Tilman, and Groupe Interdisciplinaire de Génoprotéomique Appliquée (GIGA)-Genomics, Domaine Universitaire Sart-Tilman (L.P., W.C., M.G.), Liège, and the Pediatric Endocrinology Unit, Department of Pediatrics, Clinique Universitaire Saint-Luc, Université Catholique de Louvain, Louvain (P.A.L.) - all in Belgium; School of Health and Biosciences, Pontifícia Universidade Católica do Paraná, Curitiba (F.R.F., R.B.A.), and Department of Endocrinology, Faculty of Medicine, University of Brasilia, Brasilia (L.A.N.) - both in Brazil; Departments of Molecular and Human Genetics (B.Y., P.L., J.R.L.) and Pediatrics (J.R.L.), Texas Children's Hospital (J.R.L.), Baylor College of Medicine, Houston; Department of Anatomical and Cytological Pathology, Hôpital Foch, Suresnes (C.V.), INSERM Unité 1016, Institut Cochin, Université Paris Descartes, Hôpital Cochin, Service d'Endocrinologie, Paris (C.V., J.B.), Assistance Publique-Hôpitaux de Paris, Hôpitaux Universitaires Paris-Sud, Service d'Endocrinologie et des Maladies de la Reproduction et Centre de Référence des Maladies Endocriniennes Rares de la Croissance, and Université Paris Sud 11, Faculté de Médecine, UMR-S693, Le Kremlin-Bicêtre (P. Chanson, P.K.), and Aix-Marseille Université, Centre National de la Recherche Scientifique, UMR-7286, Centre de Recherche en Neurobiologie et Neurophysiologie de Marseille, Marseille (A. Barlier) — all in France; Department of Endocrinology, King Edward Memorial Hospital, Mumbai, India (N. Shah); Endocrinology and Diabetes Unit, BC Children's Hospital, Vancouver, British Columbia (D.M.), and the Division of Endocrinology, Hospital for Sick Children, Toronto (I.L.) — both in Canada; Endocrinology and Diabetology Unit, Fondazione Istituto de Ricovero e Cura a Carattere Scientifico Ca' Granda Ospedale Maggiore Policlinico, Milan (E.F.), and Section of Endocrinology, Department of Medical Sciences, University of Ferrara, Ferrara (M.C.Z.) - both in Italy; Endocrinological Research Center, Institute of Pediatric Endocrinology (N. Strebkova), and Burdenko Neurosurgery Institute (N.M.) - both in Moscow; Department of Pharmacology and Physiology, George Washington University (A.H.), and Department of Chemistry and Center for Behavioral Neuroscience, American University (S.C.) - both in Washington, DC; Department of Paediatric Endocrinology, Princess Margaret Hospital for Children and School of Pediatrics and Child Health, University of Western Australia, Perth, Australia (C.S.C.); and Institute for Science and Technology in Medicine, Keele University, Guy Hilton Research Centre, Stoke-on-Trent, United Kingdom (W.E.F.).

REFERENCES

1. Veldhuis JD, Iranmanesh A, Erickson E, Roelfsema F, Bowers CY. Lifetime regulation of growth hormone $(\mathrm{GH})$ secretion. In: Fink G, Pfaff DW, Levine JW, eds. Handbook of neuroendocrinology. New York: Academic Press, 2012:237-55.

2. Beckers A, Aaltonen LA, Daly AF, Karhu A. Familial isolated pituitary adenomas (FIPA) and the pituitary adenoma predisposition due to mutations in the aryl hydrocarbon receptor interacting protein (AIP) gene. Endocr Rev 2013;34:239-77.

3. Stratakis CA, Tichomirowa MA, Boikos $\mathrm{S}$, et al. The role of germline AIP, MEN1, PRKAR1A, CDKN1B and CDKN2C mutations in causing pituitary adenomas in a large cohort of children, adolescents, and patients with genetic syndromes. Clin Genet 2010;78:457-63.

4. Daly AF, Jaffrain-Rea ML, Ciccarelli A, et al. Clinical characterization of familial isolated pituitary adenomas. J Clin Endocrinol Metab 2006;91:3316-23.

5. Xekouki P, Azevedo M, Stratakis CA. Anterior pituitary adenomas: inherited syndromes, novel genes and molecular pathways. Expert Rev Endocrinol Metab 2010;5:697-709.

6. Tatton-Brown K, Rahman N. Sotos syndrome. Eur J Hum Genet 2007;15:264-71.

7. Gurrieri F, Pomponi MG, Pietrobono $\mathrm{R}$, et al. The Simpson-Golabi-Behmel syndrome: a clinical case and a detective story. Am J Med Genet A 2011;155A:145-8. 8. Gläsker S, Vortmeyer AO, Lafferty AR, et al. Hereditary pituitary hyperplasia with infantile gigantism. J Clin Endocrinol Metab 2011;96(12):E2078-E2087.

9. Espiner EA, Carter TA, Abbott GD, Wrightson P. Pituitary gigantism in a 31 month old girl: endocrine studies and successful response to hypophysectomy. J Endocrinol Invest 1981;4:445-50.

10. Bergamaschi S, Ronchi CL, Giavoli C, et al. Eight-year follow-up of a child with a GH/prolactin-secreting adenoma: efficacy of pegvisomant therapy. Horm Res Paediatr 2010;73:74-9.

11. Leontiou CA, Gueorguiev M, van der Spuy J, et al. The role of the aryl hydrocarbon receptor-interacting protein gene in familial and sporadic pituitary adenomas. J Clin Endocrinol Metab 2008;93:2390-401. 12. Sali A, Overington JP. Derivation of rules for comparative protein modeling from a database of protein structure alignments. Protein Sci 1994;3:1582-96.

13. Bates B, Zhang L, Nawoschik S, et al. Characterization of Gpr101 expression and G-protein coupling selectivity. Brain Res 2006;1087:1-14.

14. Lee DK, Nguyen T, Lynch KR, et al. Discovery and mapping of ten novel G protein-coupled receptor genes. Gene 2001;275:83-91.

15. Lowell BB, Dhillon H. Patents: novel gpr101 transgenic mice and methods of use thereof. 2011 (http://www.google.com/ patents/US20110173706).

16. Madrigal I, Fernández-Burriel M, Rodriguez-Revenga L, et al. Xq26.2-q26.3 microduplication in two brothers with intellectual disabilities: clinical and molecular characterization. J Hum Genet 2010;55:822-6.

17. Mфller RS, Jensen LR, Maas SM, et al $\mathrm{X}$-linked congenital ptosis and associated intellectual disability, short stature, microcephaly, cleft palate, digital and genital abnormalities define novel Xq25q26 duplication syndrome. Hum Genet 2014;133: 625-38.

18. Stankiewicz P, Thiele $H$, Schlicker $M$, et al. Duplication of Xq26.2-q27.1, including SOX3, in a mother and daughter with short stature and dyslalia. Am J Med Genet A 2005;138:11-7.

19. Zhang F, Khajavi M, Connolly AM, Towne CF, Batish SD, Lupski JR. The DNA replication FoSTeS/MMBIR mechanism can generate genomic, genic and exonic complex rearrangements in humans. Nat Genet 2009;41:849-53.

20. Regard JB, Sato IT, Coughlin SR. Anatomical profiling of $\mathrm{G}$ protein-coupled receptor expression. Cell 2008;135:561-71. 21. Cho-Clark M, Larco DO, Semsarzadeh NN, Vasta F, Mani SK, Wu TJ. GnRH-(1-5) transactivates EGFR in Ishikawa human endometrial cells via an orphan $\mathrm{G}$ proteincoupled receptor. Mol Endocrinol 2014;28: 80-98.

22. Nilaweera KN, Ozanne D, Wilson D, Mercer JG, Morgan PJ, Barrett P. G proteincoupled receptor $101 \mathrm{mRNA}$ expression in the mouse brain: altered expression in the posterior hypothalamus and amygdala by energetic challenges. J Neuroendocrinol 2007;19:34-45.

23. Vissers LE, Pawel S. Microdeletion and microduplication syndromes. In: Feuk L, ed. Genomic structural variants: methods and protocols. Hatfield, Hertfordshire, United Kingdom: Humana Press, 2012:29-76.

24. Kurth I, Klopocki E, Stricker S, et al. Duplications of noncoding elements $5^{\prime}$ of SOX9 are associated with brachydactylyanonychia. Nat Genet 2009;41:862-3.

25. Nord KH, Lilljebjörn H, Vezzi F, et al. GRM1 is upregulated through gene fusion and promoter swapping in chondromyxoid fibroma. Nat Genet 2014;46:474-7. 26. Peverelli E, Mantovani G, Lania AG, Spada A. cAMP in the pituitary: an old messenger for multiple signals. J Mol Endocrinol 2014;52:R67-R77.

27. de Herder WW. Acromegaly and gigantism in the medical literature: case descriptions in the era before and the early years after the initial publication of Pierre Marie (1886). Pituitary 2009;12:236-44.

28. Behrens LH, Barr DP. Hyperpituitarism beginning in infancy: the Alton giant. Endocrinology 1932;16:120-8.

Copyright (c) 2014 Massachusetts Medical Society. 